Carlos Alberto Pérez-Ramírez

Doctor en Ciencias Ambientales

Universidad Autónoma del Estado de México

México

[rs.capr@gmail.com]

IVONNE CONTRERAS DE LA TORRE Licenciada en Ciencias Ambientales Universidad Autónoma del Estado de México

México

[gloriaivonne15@gmail.com]

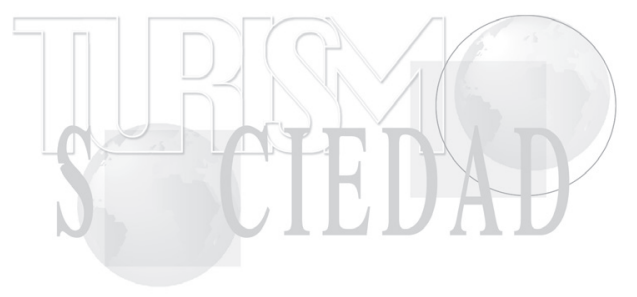

\section{DIAGNÓSTICO TURÍSTICO LOCAL PARA EL ECOTURISMO COMUNITARIO EN SAN ILDEFONSO (IXTLAHUACA, MÉXICO) ${ }^{1}$}

\section{LOCAL TOURIST DIAGNOSIS FOR COMMUNITY-BASED ECOTOURISM IN SAN ILDEFONSO (IXTLAHUACA, MEXICO)}

1 Fecha de recepción: 8 de julio de 2016

Fecha de modificación: 13 de diciembre de 2016

Fecha de aceptación: 13 de marzo de 2017

Para citar el artículo: Pérez-Ramírez, C. y Contreras, I. (2017). Diagnóstico turístico local para el ecoturismo comunitario en San Ildefonso (Ixtlahuaca, México). Turismo y Sociedad, XXI, pp. 27-49. DOI: https://doi.org/10.18601/01207555.n21.02

\section{Resumen}

Frente a la complejidad ambiental actual, es preciso avanzar en la delineación de estrategias productivas que contribuyan a la conservación y valorización del medio natural, así como al mejoramiento de las condiciones de vida y al bienestar social de la población. En el caso de la comunidad de San Ildefonso, ubicada en el municipio de Ixtlahuaca, estado de México (México), existen recursos naturales y culturales que pueden impulsar el desarrollo del ecoturismo como alternativa económica para los actores locales soportada en el adecuado aprovechamiento de los recursos. En este sentido, el artículo analiza las condiciones para impulsar el ecoturismo comunitario en la localidad con la finalidad de favorecer el desarrollo sustentable. Para ello, se retoman las aportaciones de López (2003), para determinar la potencialidad a partir de un modelo de desarrollo turístico integrado. Con base en los resultados obtenidos, es posible identificar la existencia de recursos naturales y culturales con un potencial turístico, que pueden propiciar el desplazamiento de turistas. Además, los visitantes de la región muestran interés por conocer dicha localidad, al tiempo que la población local cuenta con disposición de participar en un proyecto de ecoturismo comunitario.

Palabras clave: Sustentabilidad, ecoturismo comunitario, desarrollo comunitario, diagnóstico turístico, conservación ambiental.

\begin{abstract}
Current environmental complexity requires progress to the delineating of strategies that contribute to the conservation and enhancement of the natural environment and social welfare. Such is the case of the community of San Ildefonso, located in the municipality of Ixtlahuaca, state of Mexico (Mexico), which presents a deteriorating situation of their natural resources due to improper use of them, influencing the detriment of the quality of life of the population, from the limited economic
\end{abstract}


opportunities, social fragmentation and lack of organization to solve common problems. To solve the problem, it is possible to boost community-based ecotourism as a strategy for environmental conservation and social welfare, as it is a form of compatible tourism with sustainable development that influences in the economic revitalization of a certain region from the appropriate use of its resources. This paper aimed to analyze the conditions to promote community-based ecotourism in San Ildefonso, to promote sustainable development. Therefore, the contributions of Lopez (2003) are used to determine a local tourist diagnosis. Based on the results it is possible to identify natural and cultural resources with tourism potential, which may encourage the displacement of tourists. In addition, visitors from the region have shown interest in knowing the community; moreover, the local population has the will to participate in a community-based ecotourism project.

Keywords: Sustainability, community-based ecotourism, community development, tourist diagnosis, environmental conservation.

\section{Introducción}

La problemática ambiental actual, caracterizada por la contaminación de los recursos naturales, la deforestación, el cambio de uso de suelo, la pérdida de especies de flora y fauna, el cambio climático, entre otros, aunad[a] a los problemas sociales y al déficit del crecimiento económico, precisa la generación de nuevos paradigmas (Contreras, 2016, p. 5). Se requieren también nuevas estrategias y acciones que ayuden a dar solución a tales situaciones, con especial énfasis en los espacios rurales, que además afrontan condiciones de pobreza, marginación, ausencia de servicios públicos y de salud, falta de empleo y bajos ingresos económicos, las cuales limitan la calidad de vida de los actores locales (Contreras, 2016).
"Las alternativas necesarias para la resolución de estas problemáticas pueden estar sustentadas en el paradigma del desarrollo sustentable, que integra las variables económica, social y ambiental para elevar la calidad de vida de la sociedad" (Contreras, 2016, p. 5). En este contexto, el ecoturismo -conceptualizado como una actividad que prioriza el adecuado aprovechamiento recreativo de los recursos y el respeto por las dinámicas y prácticas socioculturales de los residentes locales- puede contribuir al desarrollo sustentable mediante prácticas y acciones tendientes a la conservación ambiental, de la biodiversidad y los valores locales. Esta modalidad se reconoce como resultado del cambio de la perspectiva de los turistas respecto de la elección de sus destinos turísticos, de la realización de actividades en el contacto directo con la naturaleza y de la interacción adecuada con el entorno (Nicolae, Nicolae, Nicolae, Pistalu y Constantinescu, 2015; Hernández y Rosas, 2010; Orgaz y Castellanos, 2013).

No obstante, el propio desarrollo de la actividad turística en el medio rural ha sido cuestionado como una práctica que dista de ser sustentable en su totalidad, debido a que puede reproducir las mismas tendencias, impactos y transformaciones del turismo convencional. La inadecuada planificación de la actividad puede generar una intensificación en el uso recreativo de los recursos, pues no garantiza el control de la afluencia de visitantes e incide en la vulnerabilidad de los recursos (Erdeli y Dinca, 2011; Eshliki y Kaboudi, 2012; Brenner y Vargas del Río, 2010). Además, puede favorecer una inadecuada integración de los actores que intervienen, la fragmentación social y limitada participación de la población local, contribuyendo al proceso de descampesinización, aculturación y transformación socioterritorial en el ámbito rural, en detrimento de la calidad de vida de los actores locales (Thomé Ortiz, 2008; Blàz- 
quez y Cañada, 2011; Gavrila-Paven, Mircea y Dogaru, 2015; Bringas y Ojeda, 2000).

A pesar de estas contradicciones, inherentes al propio desarrollo de la actividad, es posible considerar el ecoturismo como una alternativa que puede contribuir efectivamente para la conservación ambiental y el mejoramiento de las condiciones de vida de la población, puesto que representa una oportunidad para la diversificación productiva y el adecuado aprovechamiento de los recursos mediante la integración de las dimensiones económicas, políticas, culturales, la participación social, para la relación hombre-naturaleza de carácter positivo con el entorno biofísico (Nicula y Spânu, 2014).

Sobre el ecoturismo se han realizado diversas aportaciones. Se destacan las contribuciones de De Almeida y Suguio (2011) respecto a la importancia del análisis de la dinámica de la actividad con la finalidad de proponer alternativas para el impulso de la conservación y el adecuado aprovechamiento de los recursos. Por su parte, Vargas del Río y Brenner (2013) destacan la indispensable integración de las comunidades locales y de los actores externos para su afianzamiento como alternativa productiva local. Lara (1999) propone que el ecoturismo constituye un soporte para la permanencia y sustentabilidad de otras estrategias productivas, tales como la silvicultura, la agroecología, la educación ambiental y la investigación científica. Incluso Dickinson, Pinkus, Pinkus y Ramón (2015) han estudiado el impacto del impulso oficial al ecoturismo y la limitada percepción de los actores sociales respecto al mejoramiento de sus condiciones de vida a nivel local.

"A nivel mundial, el ecoturismo representa una de las actividades productivas que puede $[\mathrm{n}]$ contribuir positivamente en la mejora de las economías locales y a la reducción de la pobreza" (Contreras, 2016, p. 6). Este segmento ha crecido significativamente en los últimos años, con tasas entre $20 \%$ y $34 \%$ anual. Se estima que actualmente representa el $7 \%$ del total del turismo mundial, pero que podría crecer hasta el $25 \%$ del mercado global de viajes para el año 2020, representando ingresos por USD 470 billones por año, y ocupar el $3.6 \%$ de los empleos en el sector, lo cual puede reflejarse en la generación de ingresos destinados a mejorar la calidad de vida de las poblaciones locales, así como a la preservación de los atractivos naturales y culturales alrededor del mundo (CREST, 2015).

En el caso de México, debido a la amplia diversidad biológica, paisajes naturales -incluyendo aquellos protegidos como áreas naturales-y la riqueza cultural revelada en las manifestaciones artísticas -como las fiestas, la música, la danza, la alimentación tradicional, las edificaciones históricas y la permanencia de numerosos pueblos indígenas-, el ecoturismo constituye una importante estrategia para la diversificación del sector, la generación de ingresos económicos, la promoción de la educación ambiental y la investigación científica. "Además, se reconoce que tiene un amplio potencial para el desarrollo de la actividad, favoreciendo la participación e integración de las comunidades, la cooperación, [la] responsabilidad, [el] compromiso social y, sobre todo, la protección y conservación ambiental" (Aguilar y Pons, 2006, citados por Contreras, 2016, pp. 7-8). Se estima que existen más de:

[...] 390 destinos para la práctica de alguna de las actividades que conforman esta modalidad de turismo, entre ellos se encuentran Barrancas del Cobre en Chihuahua, Corredor de Baja California, Ventanilla en Oaxaca, Reserva de la Biosfera de la Mariposa Monarca en Michoacán, Sierra Gorda en Querétaro, Selva del Marinero en Veracruz, Escudo Jaguar en Chiapas, Parque Ecoalberto en Hidalgo y Cuetzalán en Puebla, entre otros. (Palomino y López, 2007, citados por Contreras, 2016, pp. 7-8). 
"De la misma manera, en el estado de México es posible impulsar el desarrollo del ecoturismo, soportado en los recursos naturales y culturales que posee, caracterizados por su importancia ecológica" (Contreras, 2016, p. 8), estética, cultural y para el desarrollo de la sociedad.

Se han impulsado ciertos proyectos ecoturísticos en la entidad, como el Parque Ecoturístico Tiacaque, ubicado en el municipio de Jocotitlán, y que ofrece diversos servicios para el disfrute, goce y valorización de los recursos naturales y culturales de la zona mazahua de la región norte del estado; el Parque El Borbollón, en el municipio de Temascalcingo, caracterizado por sus áreas de aguas termales, su diversidad de paisajes naturales y sus atractivos culturales de la etnia mazahua-otomí (CDI, 2012), los cuales han contribuido a la difusión de la importancia de la actividad ecoturística como estrategia para el logro de la conservación de la naturaleza y la cultura. (Contreras, 2016, p. 8).

Sin embargo, existen otras regiones con diversos recursos naturales y culturales con potencial para el ecoturismo que no han sido aprovechados para [su] desarrollo. Tal es el caso del municipio de Ixtlahuaca, [que], a pesar de la existencia de áreas forestales, agrícolas, cuerpos de agua y diversas manifestaciones culturales representadas en las festividades cívicas y religiosas, música, danza, artesanías y la gastronomía, enfrenta el deterioro ambiental debido al inadecuado aprovechamiento de sus recursos, lo que está propiciando y limitando las posibilidades para el desarrollo de la población. (Contreras, 2016, p. 9).

En este municipio se ubica la localidad de San Ildefonso, caracterizada por la presencia de cuerpos de agua, cubierta forestal y diversidad biológica propia de la región, así como [por] edificaciones históricas y diversas manifestaciones culturales, que pudieran conformar un atractivo para el desarrollo del ecoturismo comunitario. Sin embargo, presenta problemáticas ambientales importantes debido a la contaminación del agua por vertidos domésticos que no son tratados adecuadamente, la contaminación del suelo por la disposición de residuos sólidos, así como el uso excesivo y limitado control de fertilizantes y pesticidas que deterioran la calidad del suelo. Además, existen otros problemas en materia socioeconómica, como las limitadas oportunidades laborales para la población, la intensificación de los procesos migratorios y la inestabilidad social, que limitan la cohesión y participación social para la construcción de un proyecto de beneficio colectivo. (Contreras, 2016, p. 9).

Frente a estas problemáticas, el propósito general de la investigación fue analizar las condiciones existentes para impulsar el ecoturismo comunitario en San Ildefonso, por medio de un diagnóstico turístico local, a fin de fomentar el desarrollo sustentable. Es importante precisar la noción del ecoturismo que asume la investigación, que desde la perspectiva comunitaria destaca la posición central de los propios actores locales en los procesos de planificación, gestión y distribución de los beneficios generados por la actividad. Para ello, se retoman las aportaciones de López (2003), quien propone la aplicación de un modelo de desarrollo turístico integrado para las áreas del interior, para determinar la potencialidad turística.

\section{Metodología}

La presente investigación estuvo soportada en los aportes metodológicos de López (2003), quien destaca la nueva relación entre campociudad como soporte para la planificación de nuevos procesos de revitalización y dinamización socioeconómica de las áreas rurales, donde las iniciativas turísticas deben emplear métodos y metodologías adecuadas a cada 
realidad socioterritorial, que posibiliten su consolidación como un instrumento de desarrollo que conlleve la transformación social.

En este sentido, López (2003) propone el abordaje del turismo como un sistema integrado, funcional y dinámico, delineado a partir de la interrelación de elementos socioeconómicos y espaciales complejos, conformado por dos planos: a) soporte de temáticas básicas, que representan el soporte de la actividad turística integrada (aspectos territoriales, demográficos y socioeconómicos) para el conocimiento de las características y vocación del modelo turístico integrado; b) elementos del sistema turístico, conformado por los recursos territoriales (básicos o complementarios), el mercado (demanda real y potencial), las empresas (las directamente relacionadas y las que generan sinergias), así como las instituciones (facilitan la integración y la calidad de los productos).

A partir de estas aportaciones sobre el carácter turístico integrado de un espacio, fue posible establecer siete etapas para el desarrollo de la investigación:

a) Exploraciones básicas territoriales. Caracterización de las condiciones económicas, socioculturales, políticas y de relación con el entorno del lugar de estudio (López, 2003).

Además, se consideró un análisis sobre la percepción de la comunidad receptora respecto a los intereses de los actores locales para ofertar los servicios turísticos, así como los mecanismos colectivos para la distribución ampliada de los empleos y los beneficios directos o indirectos que se generen para la población residente. Para ello, se realizó la etapa de investigación de campo una vez contemplados el diseño, la prueba y la aplicación de diversos instrumentos, como el cuestionario dirigido a la población local. Dicho instrumento se aplicó a 133 personas en un período de tres meses.

b) Análisis y diagnóstico del entorno turístico (López, 2003). Inventario, evaluación y potencialidad de los recursos turísticos (cuantificación, distribución y jerarquización de los recursos), mediante la aplicación de una cédula de observación de los recursos turísticos del área de estudio, con la finalidad de identificar la potencialidad turística.

Para la identificación y la jerarquización de los recursos naturales y culturales de San Ildefonso, así como para la determinación de su potencialidad para el desarrollo del ecoturismo, se consideró la metodología propuesta por el MCIT (2010), pues permite evaluar individualmente cada uno de los recursos,

[...] mediante la asignación de puntos sobre tres variables importantes en el desarrollo turístico (calidad del recurso, apoyo complementario y significado) que, a su vez, contemplan una serie de factores, que son los que se evalúan directamente y se clasifican de la siguiente manera:

- Calidad. Son las características que hacen único al atractivo, que despiertan el interés de las corrientes de visitantes y turistas.

- Valor intrínseco es el valor del atractivo de acuerdo [con] su propia naturaleza, como escénico, artístico, científico, cultural.

- Valor extrínseco [es aquel que representa] el valor convencional del atractivo, como la magnitud o [los] factores históricos en los recursos culturales, y el uso, [la] diversidad o [la] exclusividad de los recursos naturales. 
- Estado de conservación, [que se] refiere al grado de integridad física del recurso.

- Entorno es el ambiente físico, social y cultural que rodea al recurso.

- Apoyo. Es la medida de las condiciones que favorecen y complementan el atractivo, con funciones de difusión y competitividad en el mercado.

- Acceso es la infraestructura, como [las] vías de comunicación y transporte que permiten la llegada al atractivo.

- Servicios, [los cuales] comprenden las facilidades turísticas y los servicios para la satisfacción de las necesidades de los turistas.

- Asociación con otros atractivos, [la cual se] refiere a la complementariedad del recurso por la cercanía con otros, que incide en su difusión en el mercado.

- Significado. Se refiere a la importancia o relevancia del recurso natural o cultural, de acuerdo [con] su ubicación territorial donde es reconocido.

- Local: grado de reconocimiento del atractivo a nivel municipal.

- Estatal: grado de conocimiento del recurso [que] abarca uno o más estados.

- Nacional: se refiere a que el atractivo es reconocido en el país.

- Internacional: el reconocimiento del atractivo abarca otros países (MCIT, 2010).
De acuerdo [con] estos criterios, se [realizó] la valoración individual de cada recurso natural o cultural identificado, mediante la ponderación de los valores [asignados] a cada factor [...], como se muestra a continuación. (Contreras, 2016, pp. 28-29):

Tabla 1. Evaluación y jerarquización de los recursos naturales y culturales con potencial turístico

\begin{tabular}{|c|c|c|}
\hline Variable & Factor & Valor máximo \\
\hline \multirow{4}{*}{ 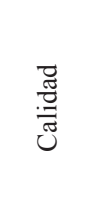 } & Valor intrínseco & 15 \\
\hline & Valor extrínseco & 15 \\
\hline & Estado de conservación & 10 \\
\hline & Entorno & 10 \\
\hline \multicolumn{3}{|l|}{50} \\
\hline \multirow{3}{*}{ 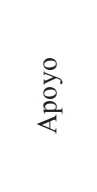 } & Acceso & 10 \\
\hline & Servicios & 10 \\
\hline & $\begin{array}{l}\text { Asociación con otros } \\
\text { atractivos }\end{array}$ & 5 \\
\hline & & 25 \\
\hline \multirow{4}{*}{ 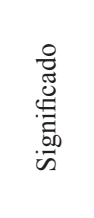 } & Local & 3 \\
\hline & Estatal & 4 \\
\hline & Nacional & 8 \\
\hline & Internacional & 10 \\
\hline \multicolumn{3}{|r|}{25} \\
\hline & Total & 100 \\
\hline \multicolumn{3}{|c|}{ Rango jerárquico } \\
\hline & Valores & Jerarquía \\
\hline & 1 a 25 & I \\
\hline & 26 a 50 & II \\
\hline & 51 a 75 & III \\
\hline & 76 a 100 & IV \\
\hline
\end{tabular}

Fuente: Elaboración propia con base en MCIT (2010).

c) Análisis de los factores que inciden en el estado de desarrollo de los recursos, 
considerando para la investigación la infraestructura de los servicios de apoyo al sistema, tales como cobertura de agua potable, energía eléctrica, drenaje, servicios de salud, de vías de transporte, entre otros.

d) Exploraciones socioturísticas sobre la demanda. Se refieren a los usuarios que hacen uso de los atractivos y servicios turísticos de un lugar, es decir, a los visitantes que generan la dinámica económica del sistema; pueden caracterizarse como locales o foráneas, o reales, potenciales y futuras. Para ello, también fueron necesarios el diseño, la prueba y aplicación de un cuestionario dirigido a los visitantes potenciales del lugar de estudio, con la finalidad de conocer el grado de interés que manifiestan ante la implementación de un proyecto de ecoturismo comunitario en San Ildefonso. En total se aplicaron 135 cuestionarios en un período de dos meses.

e) Análisis de las empresas turísticas y de aquellas que generan sinergias para el desarrollo integrado turístico. Se identificó la oferta de servicios, como alojamiento, alimentación y esparcimiento, entre otros, que existen en el lugar de estudio.

f) Gobernanza. Estrategias para la gestión de la actividad turística y que inciden directamente en la toma de decisiones para su desarrollo por medio del apoyo de diferentes instrumentos de regulación, como leyes, políticas públicas, planes o programas relacionados con el sector turismo. Está conformada por el sector público, el privado, organizaciones de la sociedad civil, los propios actores locales y demás agentes relacionados con la planificación y operación de la actividad (Launay-Gama, 2006).
Además, dado que la gobernanza se refiere al funcionamiento del sistema sociopolítico de una estructura determinada, se identificaron las relaciones existentes entre el Estado, organizaciones sociales e instituciones privadas por medio de un mapeo de actores mediante el cual se definen sus intereses, funciones, el tipo de relaciones existentes, los niveles de influencia y la disposición para participar en el desarrollo de la actividad.

g) Diagnóstico situacional del ecoturismo comunitario. Permite identificar los elementos internos y externos del sistema turístico (fortalezas, oportunidades, debilidades y amenazas), como un proceso de evaluación de cada uno de los factores que inciden en su funcionamiento (Ponce Talancón, 2007). La matriz FODA del ecoturismo comunitario en San Ildefonso retoma un enfoque cualitativo para identificar la inciden de diversos factores en los subsistemas (natural, social, económico, cultural, político y turístico), al tiempo de identificar:

[...] el grado en el que se pueden impulsar las fortalezas y potenciar las oportunidades [...], así como eliminar las debilidades y evitar las amenazas mediante acciones defensivas. (Contreras, 2016, p. 70).

A partir del análisis de los aportes metodológicos descritos, fue posible llevar a cabo las diversas etapas de investigación mediante la recopilación, la integración y el análisis de información relativa a la oferta, la demanda y las características del entorno local, con el fin de evaluar la situación, las oportunidades y limitaciones del destino, así como delinear posibles estrategias para la implementación de planes, programas, proyectos o acciones congruentes con la planificación y el desarrollo turístico sustentable en San Ildefonso. 


\section{Resultados}

\section{Exploraciones básicas territoriales}

La localidad de San Ildefonso se sitúa en el municipio de Ixtlahuaca, estado de México, ubicada en las coordenadas 193340 latitud norte, 0.994709 longitud oeste, sobre un valle con dos pequeñas elevaciones, a 2.917 msnm. El clima predominante en la región es el templado subhúmedo, con lluvias en verano. El principal cuerpo de agua es el río Lerma, que atraviesa la localidad, aunque existen algunas presas que se utilizan para riego, así como pozos y manantiales para el abastecimiento de la comunidad. Respecto a las especies de flora que se encuentran en la región, se destacan árboles como el encino, el pino, el cedro, el tepozán, el pirul y el sauce llorón, mientras que en la fauna sobresalen el zorrillo, el tlacuache, la ardilla, el hurón, la tuza, el murciélago, la lechuza, la urraca, la calandria y el gorrión, así como algunas especies de culebrillas, lagartijas y camaleones (INEGI, 2011; Sánchez, 1997).

La población de San Ildefonso es de 4.371 habitantes (2.116 hombres y 2.255 mujeres), que representa el $3.09 \%$ de la población total del municipio. La mayor parte de la población es joven, ya que el rango de edad más significativo es el de 15 a 64 años, que representa el $64 \%$ de la población total. El municipio presenta un nivel de escolaridad promedio hasta el segundo año de secundaria gracias a la cercanía que tiene con la cabecera municipal y a las posibilidades de acceder a una institución educativa. La actividad económica de la región se destaca a partir de la construcción del tramo del ferrocarril de la ruta México-Uruapan y la estación de tren, que fue inaugurado en 1883 sobre el kilómetro 3.4 de la carretera Ixtlahuaca-San Felipe del Progreso. A partir de entonces, la población se empleó en el traslado de materias primas y productos. Hoy la población económicamente activa representa el $37.54 \%$ del total, y la principal actividad económica es el cultivo de maíz, frijol, calabaza, trigo, haba, cebada y alfalfa; también se crían vacas, borregos, cerdos, caballos, pollos y guajolotes. Además, la población se emplea en trabajos de albañilería en instalaciones hidrosanitarias, eléctricas y exteriores (INEGI, 2011; Sánchez, 1997).

La principal autoridad local está compuesta por:

[...] el delegado municipal y [el] subdelegado, que son el auxiliar y el enlace que existe entre el Gobierno municipal y la comunidad. Esta autoridad tiene entre sus funciones atender las demandas de la población, promover la realización de obras de beneficio colectivo, vigilar el orden y la seguridad pública, preocuparse por los servicios e infraestructura de salud pública, atender el ramo educativo, así como la realización de actos cívicos y la organización de algunos otros eventos de importancia para la comunidad. (INEGI, 2011; Sánchez, 1997; citados por Contreras, 2016, p. 19).

Respecto al análisis sobre la perspectiva de los actores locales, se destaca el reconocimiento de los problemas ambientales, económicos y sociales que se viven. Sin embargo, a pesar de compartir intereses comunes, existe una limitada articulación de estrategias de solución y organización comunitaria, la cual se genera por la dispersión laboral, estrechas posibilidades económicas y el desconocimiento o la falta de información del beneficio de las acciones sumadas. A pesar de estas restricciones, la población muestra interés por el aprovechamiento ecoturístico de sus recursos naturales y culturales como una estrategia para la puesta en marcha de iniciativas que posibiliten la generación de beneficios compartidos. Además, la población reconoce la importancia de la conservación 
ambiental, aunque desconoce las acciones que podrían implementarse para evitar la degradación de los recursos naturales.

Se destaca que más del $90 \%$ de la población tiene interés en la creación de un destino para el ecoturismo en terrenos pertenecientes a la localidad como parte de un proyecto colectivo que beneficie a todos sus habitantes. Así mismo, existe una amplia disposición a participar en la planificación y operación de dicho proyecto, puesto que el $94 \%$ considera posible su inclusión como guías locales, para la oferta de actividades recreativas, recorridos a caballo, la realización de campamentos y juegos al aire libre, la comercialización de alimentos y productos característicos de la región, trabajos de mantenimiento de la infraestructura y equipamiento, e incluso en la promoción del ecoturismo con usuarios potenciales.

Hay una significativa aceptación del ecoturismo por parte de la comunidad receptora, dado que el $96 \%$ de las personas considera que podría diversificar sus actividades económicas; además, el $88 \%$ se refiere a su contribución para la conservación ambiental y el adecuado aprovechamiento de los recursos naturales y culturales. Incluso se indica que el desarrollo de esta modalidad turística podría favorecer la educación ambiental no solo de las corrientes de turistas y visitantes, sino también de la propia población local, propiciando la creación de espacios naturales y culturales que podrían incidir en el pleno desarrollo de la población infantil y juvenil.

De esta forma, la mayoría de los habitantes de San Ildefonso muestra interés por el desarrollo de actividades ecoturísticas en su comunidad, pues reconoce que tiene potencial para la puesta en marcha de actividades recreativas y educativas que favorezcan la conservación de sus recursos naturales, la promoción de valores positivos en los habitantes, la revalorización de sus elementos culturales propios y la inclusión de diversos sectores de la población, sin distinción de género o edad, de forma que sea posible la distribución ampliada de los beneficios generados.

\section{Análisis y diagnóstico del entorno turístico}

"La comunidad de San Ildefonso posee recursos con potencial turístico, tanto naturales como culturales, que pueden constituirse como detonantes de las corrientes de turistas y visitantes al lugar" (Contreras, 2016, p. 50). La identificación y caracterización del lugar se llevó a cabo mediante la cédula de observación de recursos naturales y culturales. Se destacan los siguientes recursos con potencial turístico:

Recursos naturales:

- Presa de Santa Bárbara. Ubicada en los límites de la comunidad de San Ildefonso y El Rincón de Los Perales, perteneciente al ejido de San Ildefonso, a cargo del comisariado ejidal. La vía de acceso es terracería, no cuenta con señalización y mantiene un buen estado de conservación. Este cuerpo de agua es utilizado para el riego de los cultivos de maíz colindantes y no se han instrumentado estrategias para su conservación.

- Loma del Toro. Corresponde a una de las elevaciones de la localidad y colinda con la comunidad de El Rincón de los Perales, también pertenece el ejido de San Ildefonso. La vía de acceso es terracería y no cuenta con servicio de transporte público. En este lugar operó un relleno sanitario que concluyó su vida útil, y ahora es utilizado para la realización de actividades recreativas como recorridos en bicicleta y el alquiler de caballos, así como para actividades de convivencia familiar. Sin embargo, la afluencia de visitantes ha 
propiciado la contaminación por residuos sólidos, la degradación de la vegetación e incluso la generación incidental de incendios forestales.

- La Ladera. Elevación ubicada en el ejido de la misma localidad, colindante con la comunidad de San Lorenzo Toxico. El traslado debe ser en automóvil particular, pues no existe transporte público. La vía de acceso es de terracería y no cuenta con señalización. En este sitio se encuentran dos presas, una de ellas es conocida como la presa de Maro y la otra como la presa de San Lorenzo, ambas se utilizan para el riego de cultivos de los predios cercanos y como destino de visita de algunas familias de la propia comunidad. Su estado de conservación es regular, pues se registran la disposición inadecuada de residuos sólidos y la eutrofización de los cuerpos de agua.

- Actividades agropecuarias tradicionales. Si bien constituyen el sector económico predominante de subsistencia para la localidad, también pueden ser un recurso natural de interés para el turismo, pues además del cultivo tradicional de maíz se desarrollan otros procesos productivos, como los huertos familiares y la ganadería de traspatio, en las que se crían especies domésticas, como vacas, caballos, ovejas, cerdos, gallinas, guajolotes, patos, entre otros, que pudieran ser de interés para los visitantes. El uso y el manejo de cada parcela dependen de su propietario, y es posible identificar determinados predios con deterioro de sus suelos por el uso excesivo de fertilizantes y nulas técnicas de agricultura ecológica o rotación de cultivos.

Recursos culturales:

- Antigua estación del ferrocarril. Construcción de principios del siglo XX con- siderada como inmueble histórico por el Instituto Nacional de Antropología e Historia (INAH). La vía de acceso es la carretera estatal Ixtlahuaca-San Felipe del Progreso, por lo que se puede acceder al sitio en transporte público o en automóvil particular. "A diferencia de su funcionalidad original, actualmente solo se utiliza como bodega para algunas herramientas auxiliares de las vías del ferrocarril" (Contreras, 2016, p. 53). El estado de conservación de este inmueble es regular, puesto que cuenta con mantenimiento constante.

- Iglesia de San Ildefonso. Construida en 1948 y ubicada en el núcleo urbano de la localidad. Está a cargo de la Fiscalía de la comunidad, entidad responsable de su cuidado. La vía de acceso es pavimentada. El inmueble cuenta con los servicios públicos de energía eléctrica, agua potable y drenaje. En este espacio se realizan gran parte de las actividades religiosas de la población, como las misas dominicales y las fiestas patronales. Su estado de conservación es bueno. Esta iglesia es un ícono de identidad para los locales, por eso se generan acciones para el cuidado y mantenimiento de sus instalaciones (Contreras, 2016, p. 54).

- Festividades locales

La población lleva a cabo diferentes festividades a lo largo del año, principalmente las fiestas patronales, en [...] enero (Santo Patrón San Ildefonso) y agosto (Santo Patrón San Cayetano), la celebración de la Semana Santa, el Día de la Virgen y las festividades navideñas, entre otras. (Contreras, 2016, p. 54).

Aunque no se realizan actividades de promoción, difusión o regulación, hay una amplia participación de la población para su desarrollo, ya que representa un sólido elemento 
identitario, con un alto grado de apego para su continuación.

Por otro lado, para la determinación de la potencialidad turística de San Ildefonso, se evaluó cada uno de los recursos naturales y culturales obtenidos en el inventario por medio de su evaluación/jerarquización (Contreras, 2016) en correspondencia con las variables calidad (valor intrínseco, extrínseco, estado de conservación y entorno), apoyo (acceso, servicios y asociación con otros atractivos), así como significado (local, estatal, nacional e internacional). A partir de esta correlación, es posible estimar el potencial turístico e incluso determinar las posibles acciones que pudiesen planificarse para el desarrollo de la actividad.

Mediante esta jerarquización de los recursos naturales y culturales, se determinó la importancia de cada uno de ellos en el orden correspondiente: 1) festividades locales; 2) antigua estación del ferrocarril; 3) iglesia de San Ildefonso; 4) actividades agropecuarias; 5) Loma del Toro; 6) presa de Santa Bárbara; 7) La Ladera. (Contreras, 2016, p. 75).

De esta manera, los recursos culturales de San Ildefonso constituyen el elemento de mayor trascendencia para la planificación de actividades turísticas, atribuible a su localización, accesibilidad y disponibilidad de servicios públicos, a partir de los cuales se pueden llevar a cabo diversas estrategias que conlleven su aprovechamiento. Sin embargo, los recursos naturales son los de mayor significación para la puesta en marcha de iniciativas ecoturísticas que posibiliten al usuario la realización de actividades en contacto con la naturaleza y su participación en las actividades agropecuarias, tales como la siembra y cosecha de granos u hortalizas, la recolección de plantas y especies comestibles, el manejo de animales de traspatio, así como la apreciación del entorno boscoso, de cuerpos de agua y la práctica de actividades deportivas, recreativas y de convivencia social.

\section{Factores que inciden en el desarrollo turístico}

En el núcleo urbano de San Ildefonso se cuenta con servicios públicos de energía eléctrica, agua potable y drenaje, pero en los asentamientos dispersos su prestación es irregular. Con referencia a la disponibilidad de los recursos naturales y culturales identificados como potenciales turísticos, todos disponen de vías de comunicación para su acceso y energía eléctrica, incluso la iglesia local y la estación del ferrocarril, que cuentan con los tres servicios básicos. No obstante, se requiere la cobertura de agua potable y de drenaje, para lo cual es necesario realizar las gestiones correspondientes y el pago de derechos ante las autoridades municipales y la delegación correspondiente.

Por otro lado, "en el municipio se cuenta con servicios de salud disponibles para la población, tales como hospitales, sanatorios, clínicas, laboratorios de análisis clínicos, consultorios médicos y consultorios dentales" (Contreras, 2016, p. 63); además, la comunidad de San Ildefonso cuenta con "dos clínicas de medicina familiar y un consultorio médico particular con servicio de farmacia" (Contreras, 2016, p. 63).

Las vías de transporte representan un factor determinante para el desarrollo del ecoturismo, ya que son las vías de acceso para llegar al punto donde se ofrece tal servicio. En este contexto, la principal vialidad de la comunidad de San Ildefonso es la carretera Ixtlahuaca-San Felipe del Progreso, que conecta ambos municipios y a su vez es la vía de acceso principal para muchas de las localidades del municipio de Ixtlahuaca. De la misma manera, existe la carretera San Ildefonso, que atraviesa la zona centro de 
la localidad y conecta con varios caminos de terracería o veredas que llegan a la mayoría de [los] espacios de la comunidad, así como a los elementos del inventario de recursos naturales y culturales. (Contreras, 2016, p. 75).

\section{Exploraciones socioturísticas sobre la demanda}

Respecto al análisis de la demanda, se pudieron identificar las principales características, necesidades y expectativas de los usuarios potenciales del ecoturismo comunitario en San Ildefonso. Si bien las personas encuestadas se refieren al desconocimiento de esta modalidad turística, de sus alcances, oferta de servicios y de las actividades asociadas, perciben como aspectos positivos la posibilidad de realizar actividades en contacto con la naturaleza y la riqueza cultural de la región, que pueden favorecer la adquisición de nuevos aprendizajes respecto a la conservación de los recursos naturales, así como la valoración de elementos culturales distintos a la dinámica cotidiana que coadyuven al desarrollo integral de las personas mediante la convivencia, el esparcimiento, la recreación y el conocimiento de la diversidad en el medio biofísico y sociocultural.

De esta forma, el $70 \%$ de los usuarios potenciales (de carácter regional, provenientes de la cabecera municipal de Ixtlahuaca y de otros municipios próximos, como Toluca, Metepec, Zinacantepec, Almoloya de Juárez, Jocotitlán, Jiquipilco y Atlacomulco) considera positiva la implementación de actividades ecoturísticas en San Ildefonso, aunque desconoce los recursos naturales y culturales existentes en la localidad, por lo que es necesaria una amplia difusión de este segmento de turismo y de las características de la propia población y su entorno, esto por medio de acciones de sensibilización en turismo y cultura turística. Aun así, el
$92 \%$ expresó su interés por la existencia de un destino ecoturístico en la región que les permita adquirir nuevos conocimientos por medio de actividades de educación ambiental, mediante la realización de talleres, cursos u otras asociadas con la apreciación de la naturaleza y la cultura local, pero que, además, les permita llevar a cabo actividades distintas a su cotidianeidad, con espacios destinados para la recreación, el esparcimiento y la diversión en familia o con amigos.

Ante la posibilidad de implementar diversas actividades de ecoturismo en San Ildefonso, los usuarios potenciales destacan como factores indispensables la diversificación, la accesibilidad y la seguridad en el servicio ofertado. De esta forma, sugieren la habilitación de espacios recreativos equipados con áreas de juegos infantiles, así como para la práctica de deportes en conjunto, como fútbol, básquetbol y vóleibol. Además, deberá contar con instalaciones adecuadas para la estancia de grupos de familias y amigos; con mesabancos para la preparación de alimentos; con sanitarios, estacionamiento y vigilancia. También deberá disponer de establecimientos para la venta de alimentos, bebidas y productos artesanales característicos de la región. Es preciso considerar que, para la construcción de dicha infraestructura y equipamiento turístico, deberá retomarse un diseño soportado en la bioconstrucción y acorde con el adecuado aprovechamiento de los recursos. Por otro lado, se destaca su interés por la realización de actividades alternativas, como deportes de aventura, vinculadas con el ciclismo de montaña, gotcha, áreas de acampado, alquiler de lanchas y cabalgatas; pero además aquellas asociadas con la modalidad ecoturística, como senderismo y recorridos guiados - que posibiliten la observación de la flora y la fauna características de la región-, su participación en actividades agropecuarias, cursos y talleres de educación ambiental, así como otras actividades dirigidas a la investigación. 
Respecto a la accesibilidad en cuanto al costo, se estima importante que el precio por la contratación de alguna actividad recreativa o cultural, participación en talleres de educación ambiental y venta de alimentos deberá ser acorde con la propia realidad económica de los usuarios potenciales de la región. De esta forma, si bien se acepta la posibilidad de generar un pago que permita la operación y el mantenimiento de las instalaciones, es necesario que este corresponda a las necesidades y expectativas de los visitantes.

Del mismo modo, la seguridad del visitante constituye un factor ineludible para cualquier iniciativa, pues en el marco de violencia e inseguridad que predomina en el contexto actual en la región -y en todo el país- se debe garantizar la salvaguarda personal y de los bienes particulares para el pleno disfrute de las actividades ofertadas. Si bien es posible gestionar con las autoridades municipales la vigilancia durante el traslado de los usuarios hasta la localidad, la propia iniciativa comunitaria deberá contar con mecanismos de vigilancia y protección que brinden seguridad durante la estancia en el lugar.

\section{Oferta de servicios para el turismo}

Si bien en la actualidad la localidad de San Ildefonso no cuenta con la oferta de servicios turísticos destinados para las corrientes de turistas y visitantes, es posible considerar la oferta de servicios pertenecientes a localidades colindantes como soporte para el desarrollo de la actividad, así como los ubicados en el trayecto al lugar, con la posibilidad incluso de ampliar los beneficios económicos que genera. De esta forma, entre los servicios de alojamiento se encuentran cuatro hoteles ubicados principalmente en la cabecera municipal y en la carretera Toluca-Atlacomulco, así como dos posadas familiares situadas en el centro. De la misma manera, en las localidades aledañas El Rincón de los Perales y San Miguel Enyege se en- cuentran otros establecimientos de hospedaje. En cuanto a los servicios de alimentación en el municipio, hay diversos establecimientos que ofrecen preparación de alimentos a la carta, comida corrida, tradicional mexicana, pescados y mariscos, pizzas, comida rápida, cafeterías, fuentes de sodas, neverías, entre otros, ubicados sobre todo en la cabecera municipal y algunos otros a lo largo de la carretera Ixtlahuaca-San Felipe del Progreso. También se encuentran algunos servicios complementarios, como centros deportivos y parques urbanos.

Respecto a la oferta de actividades culturales, se destaca la existencia de la Casa de Cultura "José Donaciano Morales", ubicada a un costado del H. Ayuntamiento de Ixtlahuaca, en la cabecera municipal. En este lugar se llevan a cabo diversas actividades que van desde la impartición de cursos permanentes de danza folclórica, música, pintura, escultura, manualidades, entre otros, hasta la organización de algunos eventos, como presentaciones artísticas, exposiciones fotográficas, de pintura o conmemorativas a alguna festividad llevada a cabo en el municipio, como la fiesta patronal, o algunas de carácter cívico, como aniversarios luctuosos o del natalicio de personajes ilustres del lugar.

\section{Gobernanza para el ecoturismo}

La gobernanza considera no solo la configuración y la delineación de las instituciones públicas, el proceso de construcción y la vigencia de políticas públicas, dispositivos jurídicos y otros instrumentos de planificación y gestión en materia turística, sino además es imprescindible considerar las estructuras, dinámicas e interrelaciones horizontales que se generan entre los múltiples actores involucrados.

Para el caso de [...] San Ildefonso, la gobernanza está soportada [...] por la presencia de diversos actores sociales (internos 
y externos), así como por su interacción, que representa las bases para establecer los mecanismos de acceso, control y aprovechamiento turístico de los recursos naturales y culturales. (Contreras, 2016, p. 64).

De esta forma, se destacan las instancias gubernamentales en los ámbitos federal, estatal y municipal, el delegado municipal, la Asamblea General, el comisariado ejidal y el Comité de Agua, así como diversas organizaciones locales que han mostrado interés por el desarrollo de actividades recreativas y deportivas en la región, agrupaciones religiosas y la Fiscalía, que tiene una función central para la organización de las festividades locales.

Pero, además de identificar a los diversos actores sociales que intervienen para el desarrollo del turismo en San Ildefonso, es necesario comprender las relaciones que se establecen entre ellos, con la finalidad de distinguir sus propósitos de participación, objetivos y tendencias.

Todo ello puede resumirse en un mapeo de actores clave para la comunidad (véase figura 1), el cual funciona [como] una herramienta de análisis para comprender la dinámica social de los actores involucrados en la comunidad, y con ello establecer estrategias de intervención para el diseño y puesta en marcha de iniciativas de ecoturismo comunitario. (Contreras, 2016, pp. 67-68).

Mediante este análisis, es posible estimar una gobernanza favorable para el desarrollo del ecoturismo, ya que las relaciones entre cada sector de la población resultan ser, en su mayoría, de confianza y colaboración. Es preciso reconocer los intereses y la participación de cada uno de los actores, cuya intervención puede favorecer o limitar el proceso de planificación y gestión del

Figura 1. Mapeo de actores clave de San Ildefonso

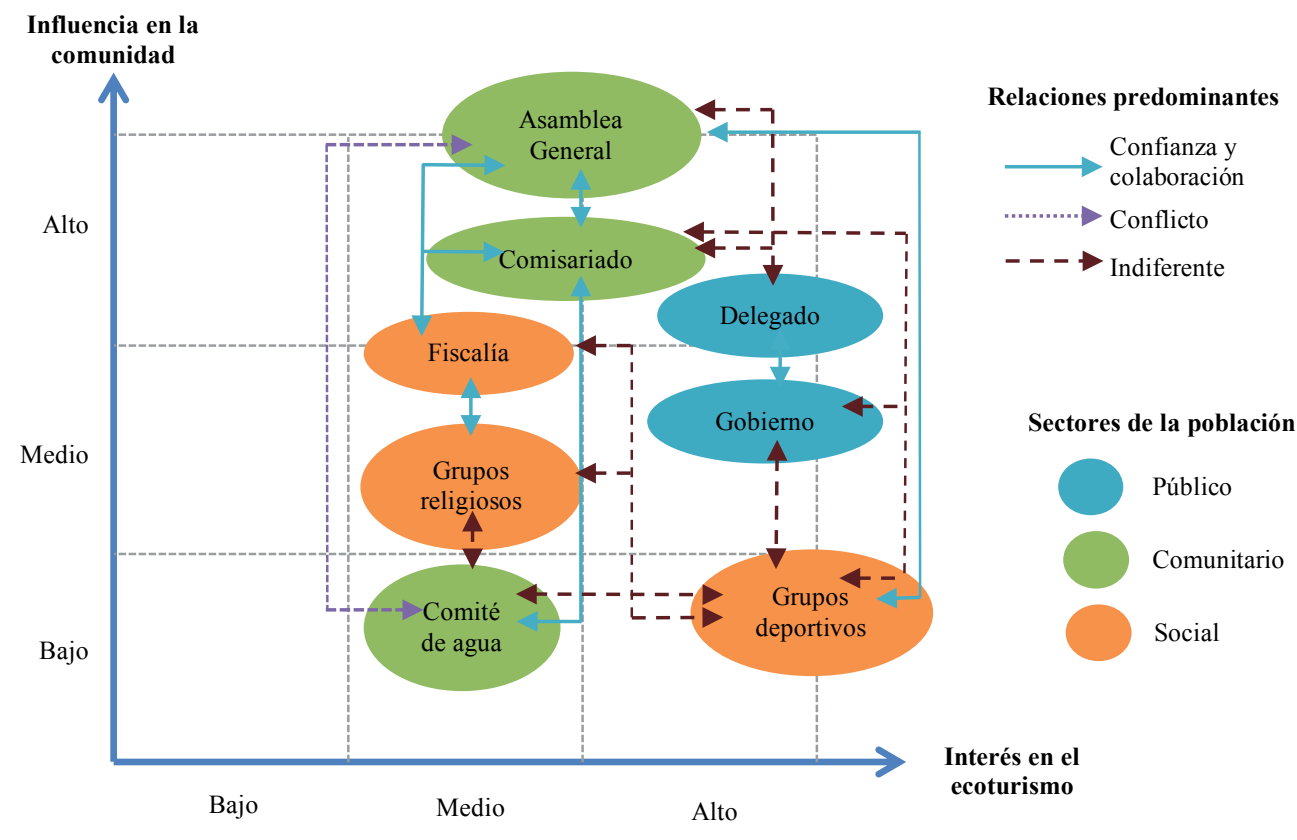

Fuente: Tomado de Contreras (2016, p. 68). 
ecoturismo. Sin embargo, [se] destaca el papel protagónico de los propios actores locales, representados por las estructuras sociopolíticas delineadas por la institucionalidad agraria, como el comisariado ejidal y el delegado municipal, pues asumen la representatividad de la población, además de conocer las problemáticas, necesidades y expectativas de la comunidad. Del mismo modo, las organizaciones deportivas y religiosas deben ser integradas en el desarrollo de la actividad, pues han mostrado interés por la diversificación de actividades [de] contacto con la naturaleza, la conservación ambiental y la continuidad [de] las prácticas, costumbres y tradiciones culturales. De esta forma, los actores que tienen mayor influencia sobre la comunidad resultan ser los que tienen también el mayor interés en el ecoturismo. (Contreras, 2016, p. 68).

Además, se reconoce la ineludible vinculación con otros actores, como los comités o las instituciones de Gobierno [...], que pueden contribuir a la delineación de una iniciativa local para el ecoturismo mediante la capacitación, asesoría y sobre todo la canalización de recursos públicos [por medio] de programas sociales, desarrollo rural, turismo y conservación ambiental, que posibiliten la creación de la infraestructura $\mathrm{y}$ [el] equipamiento necesario para la oferta de actividades y servicios complementarios, así como la promoción y publicidad del destino. (Contreras, 2016, p. 69).

"No obstante, también existen relaciones de indiferencia entre los sectores sociales y los comunitarios" (Contreras, 2016, p. 69), reveladas en la limitada interrelación entre los grupos religiosos y deportivos, relaciones que debilitan así la oportunidad de integración y vinculación para el desarrollo de acciones que favorezcan el desarrollo integral de la comunidad. "Frente a ello, es preciso delinear estrategias que posibiliten [la] integración de los actores en torno a problemáticas comunes y alternativas de solución compartidas, que propicien la generación de beneficios ampliados y el fortalecimiento de las interacciones positivas" (Contreras, 2016, p. 69).

\section{Diagnóstico situacional para el ecoturismo en San Ildefonso}

La delimitación de las características internas y externas del sistema turístico permite conocer la situación actual y las perspectivas para instrumentar estrategias que posibiliten el logro de los propósitos establecidos; por lo tanto, el análisis de las fortalezas, oportunidades, debilidades y amenazas constituye un instrumento de evaluación del ecoturismo comunitario en San Ildefonso. Para ello, se retoma cada uno de los subsistemas natural, social, económico, cultural, político y turístico, con la finalidad de determinar los alcances y las limitaciones de la planificación del ecoturismo comunitario (Contreras, 2016).

"A partir de los resultados obtenidos del diagnóstico turístico local, con relación al análisis de los recursos naturales y culturales, así como su potencial turístico, las perspectivas de la comunidad local" (Contreras, 2016, p. 75) y los usuarios potenciales,

[...] la oferta de servicios e infraestructura disponible, la gobernanza para el ecoturismo comunitario, así como el diagnóstico situacional que permite identificar elementos internos y externos de incidencia en la actividad, es posible señalar que existen posibilidades para el desarrollo de actividades ecoturísticas que posibiliten el adecuado aprovechamiento de los recursos, así como la generación de beneficios económicos para los actores locales, fortaleciendo las capacidades comunitarias para favorecer y contribuir el desarrollo sustentable. (Contreras, 2016, pp. 75-76).

Sin embargo, es necesario avanzar en la delineación de acciones concretas que impulsen 
Tabla 2. Análisis situacional del sistema comunitario de San Ildefonso

\begin{tabular}{|c|c|c|}
\hline \multirow{4}{*}{ 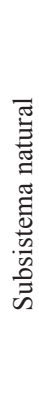 } & $\mathrm{F}$ & $\mathrm{O}$ \\
\hline & $\begin{array}{l}\text { Existencia de diversidad biológica de especies de flora y } \\
\text { fauna, cuerpos de agua y clima templado, que pueden ser } \\
\text { de interés para el desarrollo del ecoturismo. }\end{array}$ & $\begin{array}{l}\text { Disponibilidad para acceder a programas pú- } \\
\text { blicos para destinarlos a impulsar el adecuado } \\
\text { aprovechamiento de los recursos naturales y el } \\
\text { turismo en el medio rural. }\end{array}$ \\
\hline & $\mathrm{D}$ & $\mathrm{A}$ \\
\hline & $\begin{array}{l}\text { Falta de valorización de los recursos naturales por parte } \\
\text { de la comunidad, que ha propiciado la contaminación de } \\
\text { los cuerpos de agua por eutrofización y residuos sólidos. }\end{array}$ & $\begin{array}{l}\text { Problemas ambientales globales como la va- } \\
\text { riabilidad climática, emisiones a la atmósfera, } \\
\text { descarga de aguas residuales y contaminación } \\
\text { por residuos sólidos. }\end{array}$ \\
\hline \multirow{4}{*}{ 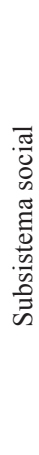 } & $\mathrm{F}$ & $\mathrm{O}$ \\
\hline & $\begin{array}{l}\text { Se ha dado continuidad a la institucionalidad agraria y a } \\
\text { la organización social, que definen la posesión colecti- } \\
\text { va de los recursos, a partir de lo cual es posible generar } \\
\text { iniciativas para el beneficio común. Además, existe una } \\
\text { comunidad participativa que ha desarrollado proyectos } \\
\text { previos de beneficio social. }\end{array}$ & $\begin{array}{l}\text { Existencia de programas y apoyos sociales para } \\
\text { el financiamiento de proyectos productivos co- } \\
\text { munitarios que benefician el mejoramiento de } \\
\text { las condiciones de vida de la población rural. }\end{array}$ \\
\hline & D & A \\
\hline & $\begin{array}{l}\text { A pesar de la existencia de una población participativa, } \\
\text { no ha sido posible la integración de los intereses comu- } \\
\text { nes para la solución de problemáticas compartidas. }\end{array}$ & $\begin{array}{l}\text { La inestabilidad económica, la violencia y la inse- } \\
\text { guridad que caracterizan al país pueden limitar el } \\
\text { desarrollo de la actividad turística en la región. }\end{array}$ \\
\hline \multirow{4}{*}{ 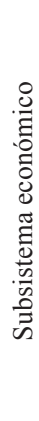 } & $\mathrm{F}$ & $\mathrm{O}$ \\
\hline & $\begin{array}{l}\text { El desarrollo del ecoturismo comunitario puede cons- } \\
\text { tituirse como una actividad complementaria para la } \\
\text { dinamización económica de la localidad mediante la } \\
\text { generación de empleos e ingresos económicos. }\end{array}$ & $\begin{array}{l}\text { El ecoturismo constituye una modalidad turís- } \\
\text { tica con marcado crecimiento en los últimos } \\
\text { años, en función de los intereses de las corrien- } \\
\text { tes de turistas y visitantes. }\end{array}$ \\
\hline & $\mathrm{D}$ & A \\
\hline & $\begin{array}{l}\text { La principal actividad económica es la agricultura de } \\
\text { temporal, con bajos rendimientos y una limitada pobla- } \\
\text { ción económicamente activa que participa en los proce- } \\
\text { sos migratorios con fines laborales. }\end{array}$ & $\begin{array}{l}\text { Frente a la compleja situación económica glo- } \\
\text { bal, los apoyos y recursos públicos destinados } \\
\text { para el desarrollo de proyectos productivos en } \\
\text { el medio rural pueden limitarse. }\end{array}$ \\
\hline \multirow{4}{*}{ 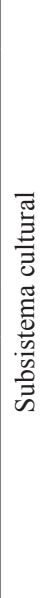 } & $\mathrm{F}$ & $\mathrm{O}$ \\
\hline & $\begin{array}{l}\text { Existen edificaciones con valor histórico en la región. } \\
\text { Además, la población ha dado continuidad a sus costum- } \\
\text { bres, tradiciones, valores y prácticas culturales, como } \\
\text { las fiestas, música, danza y alimentación tradicional, que } \\
\text { pueden ser de interés para el desarrollo de la actividad } \\
\text { turística. }\end{array}$ & $\begin{array}{l}\text { Creciente interés del turismo por los elemen- } \\
\text { tos culturales característicos de México y en } \\
\text { particular de los espacios rurales. Además, } \\
\text { los diversos sectores público, privado y social } \\
\text { desarrollan múltiples actividades con fines } \\
\text { culturales. }\end{array}$ \\
\hline & D & A \\
\hline & $\begin{array}{l}\text { A pesar de la vigencia de elementos culturales propios de } \\
\text { la comunidad, existen múltiples factores que han debilita- } \\
\text { do la identidad del pueblo indígena mazahua de la región, } \\
\text { como la participación de la población en procesos migra- } \\
\text { torios con fines laborales y educativos, la dinámica de las } \\
\text { instituciones políticas, religiosas y sociales e incluso los } \\
\text { medios de comunicación. }\end{array}$ & $\begin{array}{l}\text { La propia dinámica del turismo puede favore- } \\
\text { cer la pérdida o transformación de elementos } \\
\text { culturales propios en función de la apertura de } \\
\text { la comunidad con el exterior, la interacción con } \\
\text { actores externos, así como la adaptación de la } \\
\text { cultura en función de las necesidades y expec- } \\
\text { tativas del turismo. }\end{array}$ \\
\hline
\end{tabular}




\begin{tabular}{|c|c|c|}
\hline \multirow{4}{*}{ 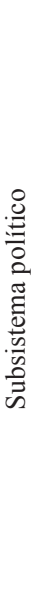 } & $\mathrm{F}$ & $\mathrm{O}$ \\
\hline & $\begin{array}{l}\text { La continuidad de la institucionalidad agraria y la } \\
\text { representatividad colectiva mediante la Asamblea y el } \\
\text { comisariado posibilitan la participación de la población } \\
\text { en la formulación de estrategias para el beneficio común. } \\
\text { Además, existe vinculación con otros actores públicos, } \\
\text { privados y sociales para el impulso del desarrollo rural. }\end{array}$ & $\begin{array}{l}\text { El marco jurídico nacional reconoce la posibi- } \\
\text { lidad de las comunidades indígenas y rurales } \\
\text { para el aprovechamiento colectivo de sus } \\
\text { recursos, además de que dispone de diversas } \\
\text { políticas públicas y programas de desarrollo } \\
\text { que pueden contribuir al fortalecimiento de } \\
\text { estructuras sociopolíticas locales. }\end{array}$ \\
\hline & $\mathrm{D}$ & A \\
\hline & $\begin{array}{l}\text { En el interior de la comunidad hay múltiples intereses } \\
\text { que pueden llevar a disputas y enfrentamientos locales } \\
\text { por el acceso y control de los recursos, además de que } \\
\text { existe desconfianza en cuanto a los intereses y la actua- } \\
\text { ción de actores externos. }\end{array}$ & $\begin{array}{l}\text { Las reformas a la configuración y posesión } \\
\text { colectiva del territorio pueden favorecer su } \\
\text { fragmentación con fines particulares, lo que } \\
\text { puede atenuar la fortaleza de las instituciones } \\
\text { locales y la participación de la población en la } \\
\text { toma de decisiones. }\end{array}$ \\
\hline \multirow{4}{*}{ 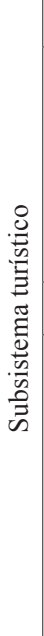 } & $\mathrm{F}$ & $\mathrm{O}$ \\
\hline & $\begin{array}{l}\text { San Ildefonso cuenta con recursos naturales y culturales } \\
\text { con potencial para el ecoturismo, interés de las corrientes } \\
\text { de turistas y visitantes por conocer la localidad, así como } \\
\text { interés de la población local por participar en proyec- } \\
\text { tos productivos que les permita contar con alternativas } \\
\text { económicas. }\end{array}$ & $\begin{array}{l}\text { Actualmente, la demanda por los servicios que } \\
\text { ofrecen una modalidad de ecoturismo se en- } \\
\text { cuentra en aumento, lo cual constituye } \\
\text { un sólido argumento para la planificación de un } \\
\text { proyecto turístico impulsado por los actores } \\
\text { locales. }\end{array}$ \\
\hline & $\mathrm{D}$ & A \\
\hline & $\begin{array}{l}\text { El turismo no se ha considerado como una alternativa } \\
\text { económica para la localidad, en tanto que se priorizan } \\
\text { otras actividades con rendimientos inmediatos. Además, } \\
\text { es necesaria la canalización de recursos públicos o de } \\
\text { la propia comunidad para la creación de infraestructu- } \\
\text { ras, equipamiento, capacitación, asesoría, promoción, } \\
\text { publicidad, así como para la gestión de las iniciativas } \\
\text { planteadas. }\end{array}$ & $\begin{array}{l}\text { La actividad turística se caracteriza por su } \\
\text { fragilidad frente a factores externos que pueden } \\
\text { alterar su desarrollo. De esta forma, la inestabi- } \\
\text { lidad económica, política, social o el deterioro } \\
\text { de los recursos naturales y culturales pueden } \\
\text { limitar sus posibilidades de desarrollo y conso- } \\
\text { lidación como alternativa económica. }\end{array}$ \\
\hline
\end{tabular}

Fuente: Contreras (2016).

la planificación y gestión del ecoturismo comunitario en la localidad, conjuntando las necesidades y aspiraciones de los actores locales con los esfuerzos provenientes del exterior, con la finalidad de favorecer el pleno desarrollo de la actividad. (Contreras, 2016, p. 76).

Para ello, se delinean a continuación una serie de estrategias que:

[...] podrían contribuir al proceso de planificación de la actividad, considerando inicialmente acciones que favorezcan la recuperación ambiental de los recursos naturales deteriorados actualmente, así como acciones tendientes al fortalecimiento de la identidad comunitaria, que posibiliten la integración de un actor colectivo que reconozca y de continuidad a sus prácticas culturales, al tiempo de posicionarse como actor protagónico en el desarrollo de la actividad.

A partir de ello, será posible la programación de cursos y talleres referentes a la temática natural y cultural que puedan incidir en el proceso de revaloración de los 
propios actores locales, pero que además se constituyan como atractivos para los usuarios potenciales. Incluso se considera oportuna la delineación de rutas turísticas que integren la oferta de servicios, así como un centro ecoturístico y de educación ambiental que favorezca la adquisición de nuevos conocimientos sobre la conservación de la naturaleza y las manifestaciones culturales locales para los actores involucrados. (Contreras, 2016, p. 76).

\section{Estrategias para el desarrollo del ecoturismo}

En correspondencia con la potencialidad para el desarrollo del ecoturismo comunitario en San Ildefonso, es preciso reconocer la participación protagónica de los actores locales en el proceso de planificación de la actividad. Por ello, es fundamental la integración de la población como poseedora de los recursos naturales y culturales, así como la principal destinataria de los beneficios que se generen. Para eso, es necesario favorecer el reconocimiento de la importancia de la participación colectiva para el bien sumado mediante estrategias y acciones que conlleven el fortalecimiento de la identidad, la cohesión social y la reciprocidad como soportes fundamentales en la construcción de una iniciativa ecoturística desde la perspectiva comunitaria.

En este sentido, se debe fortalecer el conocimiento sobre la cultura mazahua como factor central de la identidad comunitaria, mediante la difusión de sus características, costumbres, tradiciones, lengua, música, danzas, manifestaciones culturales, así como la importancia de su continuidad en las generaciones presentes. Para ello, es necesaria la realización de pláticas, exposiciones, cursos y talleres que promuevan la revalorización de los elementos propios del pueblo mazahua y la propia dinámica de la localidad. Así mismo, se deben desarrollar acciones que contemplen la difusión sobre la importancia de sus recursos naturales, como el entorno boscoso, cuerpos de agua y la continuidad de las prácticas agropecuarias, destacando los servicios ambientales que brindan, y estrategias para su preservación.

De esta manera, la comunidad irá fortaleciendo el sentido de identidad y pertenencia a su lugar de origen y residencia, y con ello se contribuirá a la valorización de los recursos naturales y culturales pertenecientes al sitio, con la pretensión de favorecer su adecuado aprovechamiento, incluyendo su configuración como atractivos turísticos.

Esta pretensión de solidez en el tejido comunitario constituye un complejo proceso a largo plazo, pero, sin duda, representa un factor ineludible para la construcción social de una acción colectiva que conlleve la búsqueda de soluciones a problemáticas compartidas y el impulso del bienestar social. Para el desarrollo del turismo en la localidad, dicha solidez también representa un pilar que permitirá la configuración de una incitativa comunitaria dirigida por una estructura local paralela a la institucionalidad agraria, que represente los intereses, las necesidades y expectativas de los actores locales, con el firme compromiso de promover la participación y distribución ampliada de los beneficios.

Así mismo, previo al despegue de la iniciativa ecoturística, es necesario planificar acciones para la recuperación ambiental de los recursos naturales de San Ildefonso que han sido alterados por agentes antropogénicos, acciones encaminadas a la reparación de los daños provocados a los cuerpos de agua, a las parcelas cultivables y a la zona arbolada de la comunidad. Ante este contexto se deben desarrollar actividades de limpieza de los cuerpos de agua contaminados por residuos sólidos, además del tratamiento de las aguas 
residuales del lugar previo a su vertido en dichos cuerpos de agua, mediante la implementación de un tratamiento in situ de las descargas domésticas.

De la misma forma, debe plantearse el adecuado uso de fertilizantes y plaguicidas químicos en los cultivos para evitar el deterioro del suelo, así como promover la rotación de cultivos y la realización de técnicas de agricultura sustentable, como el uso de sistemas de riego por goteo o el uso de la composta para la recuperación de los suelos. Han de tomarse medidas para la recuperación de la zona arbolada, que, aunque no ha sido alterada significativamente, sí ha tenido efectos por la tala, los incendios y la presencia de plagas, ante lo cual se requieren acciones como la reforestación y el monitoreo de dicha zona para su protección. También es necesario generar acciones encaminadas a la correcta disposición de los residuos sólidos en la comunidad, con la finalidad de recuperar la función ecológica, social e incluso recreativa de los ecosistemas.

Para el desarrollo de estas acciones, es ineludible la plena participación de los actores locales, así como el respaldo de otros agentes para la canalización de recursos que posibiliten la restauración ambiental. Del mismo modo, es necesaria la inclusión de otros actores para la gestión y programación de diversos cursos y talleres de capacitación dirigidos a la población local, que estimulen el interés por el desarrollo de la actividad y que se relacionen con la cultura turística, la planificación, la calidad del servicio, el manejo y la conservación de recursos naturales, guías locales y prestadores de servicios turísticos, manejo higiénico de alimentos, protección civil y primeros auxilios. Dichos cursos y talleres podrán incidir en la adquisición de nuevos conocimientos, tanto por parte de la población local como de las corrientes de turistas y visitantes. Para ello, se propone su instrumentación diferenciada por grupos de edad, inicialmente dirigidos a niños y jóvenes de la localidad, pero con alcances para el desarrollo del ecoturismo comunitario, dado que pueden formar parte de las actividades y de los servicios ofertados. Además, se pueden programar otras actividades complementarias que permitan la participación conjunta de ambos actores, como campañas de reforestación en la región, jornadas de limpieza o eventos culturales.

Por otro lado, respecto al diseño de productos turísticos diferenciados que posibiliten el adecuado aprovechamiento recreativo de los recursos naturales y culturales, se pueden planificar rutas ecoturísticas que complementen la oferta de actividades para los usuarios, al tiempo de ampliar la participación de la población local. Así, es posible la delineación de recorridos con temáticas específicas en función del interés de los visitantes, ya sea el entorno natural, la riqueza cultural o incluso recorridos mixtos. Se puede planificar una ruta que considere el desplazamiento hacia los recursos naturales de la localidad-como las elevaciones, los cuerpos de agua, el entorno boscoso- $-\mathrm{y}$ actividades vinculadas con la agricultura tradicional y de traspatio, en las que además los usuarios podrán desarrollar actividades interactivas que promuevan la adquisición de conocimientos sobre la importancia de la conservación ambiental y el adecuado aprovechamiento de los recursos. Del mismo modo, es posible diseñar una ruta cultural que contemple el desplazamiento entre el núcleo urbano y la antigua estación del ferrocarril, ruta en la que el usuario conozca la riqueza cultural del pueblo mazahua, así como la dinámica y las características propias de la localidad. Incluso es asequible la configuración de una ruta mixta que tenga en cuenta la visita a los principales recursos de las temáticas referidas.

Para la planificación de estas rutas, es necesario considerar las características físicas de los propios usuarios, por ejemplo, edad, 
condición física y movilidad, así como la accesibilidad, la distancia y los traslados entre los recursos turísticos. Además, es imprescindible considerar los intereses de la población para integrarse en la oferta de las actividades y servicios planteados, ya sea como guía para la realización de recorridos a pie, a caballo o en vehículos destinados para los traslados; para la venta de alimentos y artesanías durante el trayecto; como personal administrativo, de seguridad, de vigilancia o de mantenimiento; e incluso para la difusión y promoción de estas actividades con usuarios potenciales.

Incluso es posible valorar el aprovechamiento del entorno arbolado y los cuerpos de agua con potencial turístico para el desarrollo de un parque ecoturístico que funcione como un espacio para la realización de actividades recreativas y de esparcimiento, pero además como un centro de educación ambiental para que turistas, visitantes y la propia comunidad adquieran nuevos conocimientos sobre la importancia de la conservación de los recursos naturales y culturales. Este lugar deberá contar con instalaciones y equipamiento destinados a la satisfacción de las necesidades de los usuarios, en correspondencia con la normatividad vigente y acorde con las acciones para el uso eficiente de los recursos. Por ello, se deberá considerar el uso de técnicas de bioconstrucción para la habilitación de estacionamiento, sanitarios, caseta de acceso y control de visitantes, áreas de acampado, deportivas, zonas destinadas para la preparación y venta de alimentos, así como talleres y actividades de educación ambiental.

\section{Conclusiones}

"Frente a la compleja problemática socioambiental actual $[\ldots]$, resulta imprescindible avanzar en la delineación de estrategias [...] que contribuyan a la conservación y valorización del medio natural, así como al bienestar social y [al] mejoramiento de la calidad de vida de las personas, [por medio] de la planificación" (Contreras, 2016, p. 102) y gestión de acciones que impulsen el desarrollo sustentable.

En este contexto, el ecoturismo comunitario es una valiosa oportunidad para el adecuado aprovechamiento de los recursos naturales mediante la "valorización, [el] conocimiento, [la] preservación y [la] difusión de la importancia de la naturaleza" (Contreras, 2016, p. 102). Además, es una alternativa para la dinamización económica de las poblaciones locales, "ya que contribuye a la generación de ingresos" (Contreras, 2016, p. 102) y de empleo para las comunidades receptoras, a "la preservación de los elementos culturales locales y al mejoramiento de su calidad de vida" (Contreras, 2016, p. 102).

"A nivel mundial, esta modalidad del turismo alternativo se encuentra en una tendencia creciente" (Contreras, 2016, p. 102) debido a la diversificación de las motivaciones de los turistas y visitantes con interés en la práctica de actividades de contacto con la naturaleza y las culturas locales.

México posee un amplio potencial para el desarrollo del ecoturismo, pues cuenta con significativos recursos naturales y culturales que pueden hacer surgir la actividad. Así mismo, en el estado de México existen numerosos paisajes naturales, áreas naturales protegidas, diversidad de especies, cuerpos de agua, monumentos históricos y arqueológicos, tradiciones y costumbres locales, culturas indígenas vivas, entre otros, que pueden favorecer la puesta en marcha de iniciativas ecoturísticas que pueden ayudar en la preservación de los elementos naturales y culturales, así como la generación de beneficios para los actores locales.

Esta investigación realizó un análisis de las condiciones existentes para impulsar 
el ecoturismo comunitario en la localidad de San Ildefonso, ubicada en el municipio de Ixtlahuaca, estado de México, mediante un diagnóstico turístico local que permite identificar los alcances y las limitaciones para su desarrollo.

Si bien el lugar de estudio presenta diversas problemáticas naturales y sociales relacionadas con el deterioro ambiental, generadas por el inadecuado aprovechamiento de los recursos naturales, la contaminación de los cuerpos de agua por la descarga de aguas residuales, la inadecuada disposición final de residuos y la falta de valorización del medio natural, así como por las limitadas oportunidades económicas, difícil acceso a un empleo, que intensifica los procesos migratorios, la fragmentación social y una creciente pérdida de identidad comunitaria, es posible considerar la planificación de una iniciativa de ecoturismo como una estrategia válida para impulsar la solución de estas problemáticas y que además favorezca el desarrollo sustentable en la localidad.

A partir del inventario y potencial turístico realizado en la localidad, es posible identificar determinados recursos naturales y culturales que pueden estimular el desarrollo de la actividad, como la presa de Santa Bárbara, Loma del Toro, La Ladera, las actividades agropecuarias, la antigua estación del ferrocarril, la iglesia de San Ildefonso y las festividades de carácter religioso, los cuales poseen características singulares que pueden ser de interés para las corrientes de turistas y visitantes de la región. De la misma manera, se determinaron las perspectivas positivas de la población local y los usuarios potenciales con respecto al desarrollo del ecoturismo comunitario, la oferta de servicios y la infraestructura disponible, así como la importancia de la gobernanza ambiental para el desarrollo de la actividad. Se llevó a cabo un análisis situacional para comprender las fortalezas, oportunidades, debilidades y amenazas que existen para el impulso del ecoturismo comunitario.

A partir de los resultados obtenidos, se puede afirmar que es posible impulsar el desarrollo del ecoturismo comunitario en San Ildefonso, para lo cual es preciso avanzar en la concreción de estrategias que favorezcan su adecuada planificación mediante acciones que propicien la recuperación ambiental de los recursos naturales deteriorados y el fortalecimiento de la identidad comunitaria, la realización de cursos y talleres referentes a la temática natural y cultural, la delineación de rutas turísticas y contar con un centro ecoturístico y de educación ambiental que favorezca la conservación de la naturaleza, las manifestaciones culturales locales, el adecuado aprovechamiento recreativo, así como la distribución ampliada de los beneficios generados para los actores locales.

Si bien estas estrategias pueden favorecer el desarrollo sustentable en la localidad, se requiere la integración de otros estudios que generen acciones concretas para el desarrollo de esta actividad. Para ello, es necesaria la plena integración de los actores sociales, y en particular de la población local como protagonista en el proceso de planificación del ecoturismo, reconociendo además la importante vinculación con los sectores público y social para la delineación y despegue de las iniciativas planteadas. Además, la conservación y el adecuado aprovechamiento de los recursos naturales, así como la continuidad de las prácticas culturales locales, deberán ser los principales argumentos sobre los cuales se proyecten las actividades ecoturísticas, por encima de la exclusiva consideración económica, que conlleven la masificación y el deterioro de los recursos. Del mismo modo, si bien se reconoce la aptitud del ecoturismo como alternativa económica para la población, se debe dar continuidad a las activida- 
des productivas actuales y fortalecerlas con la intensión de favorecer la diversificación económica local desde una perspectiva ambientalmente responsable y que posibilite el impulso del desarrollo sustentable.

\section{Referencias bibliográficas}

Aguilar, P. y Pons, J. M. (Coords.) (2006). Introducción al ecoturismo comunitario (Serie Saber para Proteger) (2. ${ }^{\text {e ed. }) . ~ M e ́ x i c o: ~ S E M A R N A T . ~ R e-~}$ cuperado de goo.gl/ATW9Ym

Blàzquez, M. y Cañada, E. (Eds.) (2011). Turismo placebo. Nueva colonización turística: del Mediterráneo a Mesoamérica y el Caribe. Lógicas espaciales del capital turístico (1. ${ }^{\mathrm{a}} \mathrm{ed}$.). Managua: EDISA. Recuperado de goo.gl/UodAvt

Brenner, L. y Vargas del Río, D. (2010). Gobernabilidad y gobernanza ambiental en México. La experiencia de la Reserva de la Biosfera Sian Ka'an. Polis, 6(2), 115-154. Recuperado de goo. $\mathrm{gl} / \mathrm{BkJEod}$

Bringas Rábago, N. L. y Ojeda Revah, L. (2000). El ecoturismo: ¿una nueva modalidad del turismo de masas? Economía, Sociedad y Territorio, II(7), 373-403. Recuperado de goo.gl/ypgXJY

Center for Responsible Travel (CREST). (2015). The case for responsible travel: trends \& statistics 2015. Recuperado de goo.gl/fhNPWJ

Comisión Nacional para el Desarrollo de los Pueblos Indígenas (CDI). (2012). Parque Ecoturístico Tiacaque. Recuperado de goo.gl/SdXhP2

Contreras, G. (2016). Ecoturismo comunitario y desarrollo sustentable en San Ildefonso, Ixtlahuaca (México) (Tesis de licenciatura). Toluca: U. Autónoma del Estado de México. Recuperada de http://ri.uaemex.mx/handle/20.500.11799/58722

De Almeida, J. R. y Suguio, K. (2011). Ecoturismo científico en la planicie costera del extremo litoral sur del estado de São Paulo-Brasil. Estudios y Perspectivas en Turismo, 20(5), 1196-1213. Recuperado de goo.gl/61bgLi

Dickinson, J., Pinkus, M., Pinkus, M. y Ramón, C. (2015). Depredación y ecoturismo. Realidades de los prestadores de servicios en la Reserva de la Biosfera Ría Celestún, Yucatán. Península, 10(1), 145-161. DOI: 10.1016/j.pnsla.2015.05.004

Erdeli, G. y Dinca, A. I. (2011). Tourism - A vulnerable strength in the protected areas of the Romanian Carpathians. Procedia. Social and Behavioral Sciences, 19, 190-197. DOI: 10.1016/j. sbspro.2011.05.123

Eshliki, S. A. y Kaboudi, M. (2012). Community perception of tourism impacts and their participation in tourism planning: A case study of Ramsar, Iran. Procedia. Social and Behavioral Sciences, 36, 333-341. DOI: 10.1016/j.sbspro.2012.03.037

Gavrila-Paven, I., Mircea, B. y Dogaru, L. D. (2015). Advantages and limits for tourism development in rural area (case study Ampoi and Mure ú Valleys). Procedia. Economics and Finance, 32, 1050-1059. DOI: 10.1016/S2212-5671(15)01567-1

Hernández, N. y Rosas, J. (2010). Ecoturismo e infraestructura vial como detonante de la economía local, caso de estudio: Villa del Cárbon, 2009. Quivera, 12(2), 37-57. Recuperado de goo.gl/KYeZP9

Instituto Nacional de Geografía y Estadística (INEGI). (2011). Principales resultados del censo de población y vivienda 2010, México. Recuperado de goo.gl/dvJtYP

Lara, L. (1999). El ecoturismo: ¿una opción para las reservas forestales? Caso: unidad experimental de Caparo. Revista Forestal Venezolana, 43(1), 69-78. Recuperado de goo.gl/4fmwoL

Launay-Gama, C. (2006). El uso del concepto de gobernanza o/y gobernabilidad en Colombia (Cuaderno "Usos y desafíos del concepto de gobernanza en Colombia" - Programa Análisis 
y Evaluación de la Gobernanza). París: Instituto de Investigación y Debate sobre la Gobernanza. Recuperado de goo.gl/png7qs

López Olivares, D. (2003). El desarrollo turístico integrado en los espacios rurales de interior: su aplicación al producto de salud. Cuadernos de Turismo, 11, 107-126. Recuperado de goo.gl/aaC9j5

Ministerio de Comercio, Industria y Turismo (MCIT). (2010). Metodología para la elaboración del inventario de atractivos turísticos. Bogotá: Ministerio de Comercio, Industria y Turismo. Recuperado de: http://www.mincit.gov.co/loader php?1Servicio $=$ Documentos\&lFuncion $=$ verPdf $\&$ id $=61776 \&$ name $=$ MetodologiaInventario Turisti $\cos 2010$.pdf\&prefijo $=$ file

Nicolae, I., Nicolae, M., Nicolae, F., Pistalu, V. y Constantinescu, D. G. (2015). A model of ecotourism implemented within Comorova Forest Neptun. En $15^{\text {th }}$ International Multidisciplinary Scientific GeoConference SGEM 2015 (Book 5, vol. 2) (pp. 19-26). STEF92 Technology. Albena, Bulgaria: SGEM. DOI: 10.5593/SGEM2015/B52/ S20.003 \nhttp://www.sgem.org/sgemlib/spip. php?article6396

Nicula, V. y Spânu, S. (2014). Ways of promoting cultural ecotourism for local communities in $\mathrm{Si}$ biu area. Procedia. Economics and Finance, 16, 474-479. DOI: 10.1016/S2212-5671(14)00827-2
Orgaz, F. y Castellanos, M. (2013). Conceptualización y consideraciones en torno al ecoturismo. TURYDES. Revista de Investigación en Turismo y Desarrollo Local, 6(15), 1-12. Recuperado de goo.gl/YKXK $8 \mathrm{c}$

Palomino, B. y López, G. (2007). Evaluación 2006 del Programa Ecoturismo en Zonas Indígenas. Informe final. México, D. F.: UNAM. Recuperado de goo.gl/sdurCW

Ponce Talancón, H. (2007). La matriz FODA: alternativa de diagnóstico y determinación de estrategias de intervención en diversas organizaciones. Enseñanza e Investigación en Psicología, 12(1), 113-130. Recuperado de goo.gl/6MgzEg

Sánchez, J. (1997). Ixtlahuaca. Monografía municipal. Toluca: Gobierno del Estado de México.

Thomé Ortiz, H. (2008). Turismo rural y campesinado, una aproximación social desde la ecología, la cultura y la economía. Convergencia. Revista de Ciencias Sociales, 15(47), 237-261. Recuperado de goo.gl/TtFDJ8

Vargas del Río, D. y Brenner, L. (2013). Ecoturismo comunitario y conservación ambiental: la experiencia de La Ventanilla, Oaxaca, México. Estudios Sociales, 21(41), 32-63. Recuperado de goo.gl/E96M9s 